\title{
Ontology and School Culture: Does Legislation Influence School Culture in Centralized Education Systems?
}

\author{
Dr. Konstantinos Karampelas \\ Pedagogic Department of Elementary Education, \\ University of the Aegean, Rhodes, Greece \\ Dr. Maria Kouroutsidou and Dr. Nikolaos Raptis \\ Department of Nursery Education and Education Design Sciences, \\ University of the Aegean, Rhodes, Greece
}

\begin{abstract}
This study aims to identify linkage between the concepts of educational ontology, school culture and educational legislation. The first has to do with the basic fundamental elements of the educational system. The second has to do with the school climate and general working conditions. The third has to do with the laws abiding the system. All these complex concepts are relevant to the educational functions. However, their relationship and the way they interact have not been studied thoroughly. This study researches that relationship. The context of the research is the education system of Greece, which is recognized as being highly centralized. Through an examination of educational legal documents, the study draws a relationship linking, the three concepts in such systems. By examining the content of 435 legal documents, it concludes that their focus ontology-wise was mostly on the level of application of teaching work, instead of ideas or structures. This detailed structured implementation of school function leads to this centralized culture.
\end{abstract}

Keywords: ontology; culture; legislation; School function.

\section{Introduction}

This paper focuses on the relationship between ontology, school culture and educational legislation. These three concepts represent complex issues. Each has a direct impact in the formation of the conditions of school climate and the reality under which the schools function, thus influencing schools' effectiveness. However, research has not focused extensively on the relationship shared by these concepts and the way they are related to educational reality. This is the aim of this study (Vas, 2007). 
To define this relationship, this research will focus on the Greek educational system. More specifically, it examines the educational legislations that define the Greek schools and how they are related to culture and ontology. For that purpose, a series of legislation documents will be examined. This includes laws, bylaws, presidential charters that address schools and are relevant to school administration and operation (Newby, 2013; Pring, 2007). As with every national education system, the Greek system comprises unique characteristics and traits. It has been described in the literature as being strictly and highly centralized. This implies that many of the decisions pertaining to the functions and the educational mission of schools are taken by the central authority, or the Ministry of Education, and are not taken at the level of schools or perfectional units as is the case in other countries (OECD, 2018).

This project aims to define through models of educational ontology the way in which this central control is implemented and forms the school culture in the Greece, and in general, in any centralized national educational system. This approach first requires a study of the topics and theories concerning the three foundational concepts, ontology, school culture and legislation, examined through the prism of educational system and teaching function (Newby, 2013; Pring, 2007).

\section{Insights into the basic concepts}

The precision of the desired goal of any research project should take into thorough consideration the basic theory, literature and principle around the concepts negotiated. In this research these concepts are educational ontology, school culture and educational legislation. After pointing out the main points of them, it is important to approach their relationship (Cohen, Manion \& Morrison, 2013; Pring, 2007).

\subsection{Educational Ontology}

The concept of ontology has a long history as it can be found even in works of ancient Greek philosophy, primarily, that of Aristotle. Ontology mainly aims to define the basic ideas or concepts that serve as the foundation of a system as well as the relationships between them. Through the identification of these concepts or ideas, it is possible to clarify their meaning along with their contribution to the system's function.

According to Gruber, a "specification of a representational vocabulary for a shared domain of discourse - definitions of classes, relations, functions, and other objects - is called an ontology" (1993, p. 200). Educational ontology focuses on the greater understanding and approach employed by an educational system. It aims to indicate and state the concepts that serve as the foundation of the educational system and the way they influence teaching and learning functions (Alhawiti \& Abdelhamid, 2014; Gruber, 1993; Vas, 2007).

With educational ontology, gaining a deeper and more comprehensive understanding of the educational system has become easier. It is possible to 
obtain a detailed description of the general and specific aspects of a system, along with their possible advantages and disadvantages (Gavrilova \& Jin, 2008; Baker, Chung, \& Herman, 2009). This facilitates the promotion of a systemic and sustainable enhancement of the system. The educational system shares a dynamic interaction with the greater society, influencing it and being influenced by it. Constant reforms in the general social context of a society have an impact on the educational system, which is expected to catch up to the needs of the society to offer its members the most suitable education and qualifications. Through a study of these fundamental notions, educational ontology provides a more accurate understanding of the reforms and society's needs and the role of education (Fullan, 2016).

This approach and understanding of the system gained through ontology is attained by designing and using dynamic complex models and representations. These models present the system's fundamental concepts and the relations shared by them. These models' design follows specific steps that illustrate the conditions under which the concepts interact and lead to the development of the system in its contemporary form.

The first step in this process is to identify the relevant system or field of study. This is comprised by the field of education in this study. The next step is precise understanding of the concepts related to the system. In the case of an educational system, these concepts derive from ideas, theories, research goals and topics pertaining to education. These are enriched through the development of educational research. Subsequently, the relationship between these concepts should be clarified. This will facilitate the formation of groups or categories of concepts, which forms the following step. Further, this is followed by the clarification of relationships between categories (Baker et al., 2009; Vas, 2007).

The final step entails the classification in three levels: upper, mid and lower or domain level. The upper level includes concepts related to ideas and theories that serve as the system's foundation. In educational systems, these could be learning and literacy. The mid level includes concepts related to the infrastructure and institutions, which, in educational systems, would be concepts ministries, local authorities and assessment. Lastly, the lower level includes concepts pertaining to the implementation of the systems' functions. In educational systems, these can be the subjects taught and educators (Poli, Healy \& Kameas, 2010).

Alhawiti and Abdelhamid (2014) studied various aspects of ontological systems in education, elucidating that ontological studies from a certain field can be applied to design and employ ontological representations for another field. In other words, the research pertaining to the ontology of an educational system can be inspired by research on ontology of other areas of study or the ontology of another country's educational system.

Moreover, an ontological study serves as a concrete justification of the system's characteristics. The lack of this representation can lead to confusion concerning ideas, theories regarding the system, which may remain ambiguous. This prevents thorough understanding of the system and its improvement. 
Apart from the fact that ontology establishes a link between the functions of a system, by using models, it renders the study and implementation of the system easier. The system's foundations, structures and the way it functions is clearly approached with an ontological study. In the case of educational systems, ontology offers a clear view of the way it operates and leads to the desired outcome, learning. This facilitates the identification of aspects that require improvement or reform. Any effort to update and re-shape the educational system is supported by ontology (Fullan, 2016; Vas, 2007).

\subsection{School Culture}

Ontology, therefore, refers to concepts that define an educational system. These ideas form the main cause defining the climate prevailing in an educational system. Ontology influences and creates all behaviors, conditions, approaches, attitudes applied by educators, pupils, students and other groups involved in the teaching process. Fullan $(2004,2016)$ claimed that these constitute the basic parameters of a school culture, which reflects and describes educational reality.

This multi-faceted concept of school culture is employed by theorists in their general effort to analyze educational management and policy. It is used to study topics, such as funding, school functions, duties administration, subject selection, curricular design, clarification of teaching goals, precision of teaching approaches, educational innovation, evaluation, assessment and inspection, all of which are approached through the prism of school culture, during the decision-making process. These decisions aim to define the aspects that require reform or re-shaping in order to effect the school's improvement. Overall, a school's enhancement is considered effective, systemic and sustainable when it has an impact on and introduces change in the school culture. This requires an effective approach and reform of the culture's parameters. Any attempt at reform that overlooks parameters of school culture such as the ideas and foundational structures of educational system is likely to exert a limited influence.

The processes of precising as well as describing and analyzing the school culture are influenced by the school's interaction with other social institutions. A school's function and its effectiveness are associated with the general social context in which the school unit operates. This context is linked to the principles and ideas that concern the school, which refer to educational ontology (Vas, 2007). The context influences decisions that concern functional issues. Such issues could be personnel acquisition, educational approaches, subjects, curricula, general and specific duties of teachers, infrastructure and other elements of school culture relevant to ideas or practices. At the same time, this influences the criteria used to evaluate the school or the entire school system (Baker et al., 2009; Fullan, 2016; Hargreaves, 2001; Şenol \& Lesinger, 2018).

The moral agent of reform and ambassador of an educational culture is the educator and the school head. The impact of implementing any idea, either established or innovative, depends on its acceptance by educators. It is these individuals who are responsible for implementing the notion through and within their work. Any educator develops personal ideas, conceptions and 
vision with regard to teaching and their educator. This vision is influenced by the climate prevailing in the school, the wider society and the way in which the educators personally and the school as an organization interact (Fullan, 2004, 2016).

\subsection{Educational Legislation}

Educational legislation refers to all governmental and legal documents concerning laws, charters, bylaws that are relevant to education and its functions. Many analysts have justified its significance in school management, reform and improvement. Aldrich (1992), in his study of the British education system's history, concluded that any act of decision making is implemented through educational legislations. Legislations establish concretes decisions pertaining to the implementation of notions related to the qualifications, training and education learners are expected to gain.

Furthermore, Fang et al. (2012) and Güneş (2015), after researching cases of education law reforms in China and Turkey, concluded that educational legislation has a significant impact in dealing with social issues educational institutions face. Eckstein and Zilcha (1994) and Dissou, Didic, and Yakautsava (2016) support the view that educational contribution to economic development and social prosperity is realized through educational legislation, with a bidirectional relationship existing between the two. While education influences the general progress at the financial and social level, the general social and financial state and issues in a community influence the educational system by mediating in discussions such as funding and ideas schools are expected to promote.

According to the literature, the themes of educational legislation can be expanded in different dimensions. The first dimension pertains to the school's management and administration. This includes legal documents concerning topics such as school personnel appointment, distribution of duties among school administration members, funding, health and safety. The second dimension is related to educators, including legal documents pertaining topics such as educators' duties and privileges, the number of teaching sessions per week, leaves, salary and financial aspects and professional development. The third dimension concerns learning. This includes legal documents related to topics such as teaching subjects, teaching practices, school visits, evaluation and access to higher education (Aldrich, 1992; Dissou et al., 2016; Eckstein \& Zilcha, 1994; Fang et al., 2012; Güneş, 2015).

All these dimensions are interwoven. There are topics, which may belong to more than one dimension. The way in which these are approached in research is affected by the research's general orientation. Depending on the research goal, the dimension to which each topic belongs is justified and decided in advance (Newby, 2013). 


\subsection{Interrelating Ontology, School Culture and Legislation}

The concepts of ontology, school culture and legislation have been extensive studied by educational theorists. Their content and the significance they have in areas of educational policy, management and decision-making form complex but important issues. A number of research projects and numerous conclusions have been drawn regarding the way in which they effect the enhancement of institutions and organizations related to education. In the literature of educational ontology, however there does not seem to be an extensive effort to describe the interrelation between these concepts. Such an interrelation could be specific, related to the field of education, or even broader (Alhawiti \& Abdelhamid, 2014; Fullan, 2016; Gruber, 1993; OECD, 2018).

These three concepts interact with each other. They certainly share common aspects and dimensions. In what concerns the educational system, these concepts are related to the philosophy, approach towards the role of education in general and specifically. Initially, these ideas form the constitutive elements of educational system's ontology. Their outcome is reflected in the general climate, structure of the educational system and basic functions that form the foundation of the school culture. Legislation, in turn, is the means through which the ontological ideas and theories are implemented so that they form the structure and climate, essentially, the school culture. In short, ontology is transformed into culture through legislation (Baker et al., 2009; Dissou et al., 2016; Fullan, 2016; Niazov, 2018; Vas, 2007).

It is also necessary though to summarize the level of ontology at which this interaction with culture and legislation takes place. In other words, it would be beneficial to determine the level of ontology the central authority should focus on in forming educational legislations in order to form an appropriate school culture. The answer to this issue is contained in the content of educational legislations. It is important to examine the parts of the system, focusing on the legislation, the terms and conditions it sets, the possibilities it offers to schools, educators and all the other topics it addresses.

If a central authority establishes laws related to schools that aim to control general ideas concerning education, then it can be classified on the upper level of educational ontology. In that case, the school culture as formed is relevant to ideas established in the school unit. If the central authority establishes laws that pay attention to institutions and structures of educational system, the focus is on the mid level of educational ontology. Finally, if the central authority establishes laws that pay attention to the implementation and application of school functions, then it will focus mainly on the lower ontological level. In that case, the school culture will experience high involvement of central authority and control over the way in which the school function. This cannot be expected when the legislation focuses on the upper or mid level. The overall social and political context and its specificity should always be taken into consideration (Baker et al., 2009; Fullan, 2016; Poli et al., 2010; Schein, 2004). 


\section{The Research}

Having pointed out the main literature around the study topic, it is possible to move on to the research methodology design. Literature has to be combined with the context of the study, which in this case is the Greek Educational System. By examining the main characteristics of the system, it is possible to conclude to the main research questions and the appropriate methodological approach (Cohen et al., 2013; Hargreaves, 2001; Pring, 2007).

\subsection{The Greek Educational System}

This research focuses on the Greek educational system as an object of ontological study. The literature considers this system to be strictly and highly centralized. This signifies that many topics that concern the functions of the school unit are pre-determined in detail by the central authority, the Ministry of Education (Gkolia, Koutselios \& Belias, 2015; OECD, 2018). This significantly restricts the autonomy and flexibility of schools in many areas, whether significant or not.

At the level of teaching, many aspects are centrally decided. This is realized through teaching packages that comprise pre-designed lesson plans and even evaluation tasks. Furthermore, the teaching subjects at all levels of elementary and secondary education as well as the number of sessions per week are also pre-decided.

At the level of funding, central control is more intense as compared to other countries. The ministry arranges the budget of each school as well as the distribution of funding and manning.

Even other issues relevant to school administration, the exact duties of head teachers are pre-determined. This limits the scope of taking initiative and even differentiating the school based on the particularities of the wider social context in which it is situated. As concluded by research projects, this allows little room for the head teacher or the school to develop and exploit opportunities to upgrade the school's function to promote knowledge and new ideas (OECD, 2018).

These form the basic characteristics of the educational culture that exists in Greek schools and the Greek educational system. The Greek school culture is defined by intense central interference in areas such as funding, teaching and administration.

Having defined these characteristics of Greek education, the general relationship between ontology, the school culture and legislation of this educational system can be defined. Investigating this particular context, it would be possible to reach a general relationship between these aspects that would be applicable or could be extended to any system with high centralization such as the Greek system. The central point of study is the way in which legislation is formed in such a centralized system and the way it leads to the creation of the school culture. This should be studied from the point of view of ontology. It is necessary, therefore, to identify the way in which legislation works in ontological terms (Baker et al., 2009; Fullan, 2016; Poli et al., 2010). 
This inquiry can benefit from the level model of ontology. Identifying the levels that educational legislation addresses in a centralized system would be useful. As stated in the previous section, any legislation that addresses the issues of principles and ideas is classified as forming upper level of ontology, legislation that addresses educational structures and institutions is classified as comprising the mid level, while legislation that addresses the implementation of educational work and the application of the school's teaching function is classified as constituting the lower ontological level. The primary point of the investigation is whether legislation in highly centralized systems focuses on the upper, mid or lower level of ontology (Bass \& Riggio, 2014; Fullan, 2016; Poli et al., 2010; Vas, 2007).

\subsection{The Research Questions}

This research aimed to examine the specific relationship between ontology, school culture and legislation in the context of the Greek educational system. The research analyzed the legislations governing Greek education, which has been described by $\operatorname{OECD}(2017,2018)$ as highly being centralized. This legislation mainly includes documents such as those related to laws, presidential charters and bylaws concerning basic school and teaching functions.

The basic aim of the research is to identify the ontological levels that educational legislation in the case of centralized education systems focusses on to form relevant school culture. In order to address this aim, three research questions have been formed (Cohen et al., 2013). These questions were formed in accordance to the dimensions of educational legislation as described in the literature and theory. These dimensions are administration, educators' work and learning (Aldrich, 1992; Dissou et al., 2016). The research questions are therefore, formed as follows:

1) Which level of ontology does legislation related to school administration focus on?

2) Which level of ontology does legislation concerning educators' work focus on?

3) Which level of ontology does legislation pertaining to learning issues and performance focus on?

\subsection{Research Methodology and Data}

In light of its nature and general scope, this research belongs more in the domain of a qualitative paradigm. The data analysis follows the established process of qualitative research. The primary components of legislation were listed and were used as the codes of the research. These codes were further grouped into nodes. Further, the codes were synonymous with the topics and content of legislation (Cohen et al., 2013). The three levels of ontology formed the nodes. In brief, the data analysis was based on a classification of the codes as levels of educational ontology (Dissou et al., 2016; Fullan, 2016; Newby, 2013; Poli et al., 2010; Vas, 2007). 
The data sample comprised legal documents introduced since the 1980's. The basic reasons behind selecting this set were two. The first was the accessibility and possibility of obtaining these documents in a condition that was useful for the research purposes. The second was the relationship between a particular legislation and contemporary Greek education culture, and therefore, the current state of centralized systems (Baker et al., 2009; Fullan, 2016; Newby, 2013; OECD, 2018).

A total of 435 legal documents were collected. These were studied and coded. Then, they were grouped according to the dimensions of legislation they addressed, followed by the topics they referred to. A total of 164 were grouped in the first dimension of school administration and management. Among them, 32 concerned infrastructure and equipment, 94 general administration and duties of school members, 36 school panels and 11 health and safety. Moreover, 143 were grouped in the second dimension, referring to educators' work. Among them 49 concerned teaching topics, 15 concerned educators' schedules, 48 concerned the subjects of salary, pension and 22 concerned leaves or other work-related issues. Finally, 137 documents referred to the third dimension, learning issues and performance. Among them, 24 concerned access to tertiary education, 45 were related to the evaluation of learners or educators, 26 concerned general learning topics and 15 dealt with school visit and outdoor activities.

\section{Findings}

Overall, the findings reveal that legislations, as they were designed in accordance to the context of the highly centralized Greek educational system, mostly comprised the lower level of ontology.

More specifically, with regard to the first research question, which concerned school administration, as shown in Graph 1, extremely few documents included the higher or mid level. This was true for all sub-topics under this topic.

With regard to infrastructure and equipment, the legislations were found to focus mostly on subjects such as equipment, supervision of labs such as ICT and science. Concerning school function, many documents presented requirements and instructions such as the starting and end time of classes, intermissions and session duration. The picture was similar in documents concerning school boards as well as health and safety documents that definiens in detail the responsibilities of educators, such as supervising learners during break time, school arrival or departure.

These findings prove that intense and strict control, which exists in highly centralized systems, is achieved through a series of legal documents that define the implementation of administration, in other words, concern themselves with the lower level of ontology (Baker et al., 2009; Fullan, 2016; Newby, 2013; Poli et al., 2010). These legislations significantly restrict the role of head teachers as a considerable number of decisions and measures concerning the implementation and function of school units are pre-determined (OECD, 2018). This, in turn, leads to the formation of a highly centralized culture in school administration. 
Within such a culture, head teachers, teachers and members of the education community become significantly dependent on central authority for decisions and initiatives concerning their work and teaching role (Fullan, 2016).

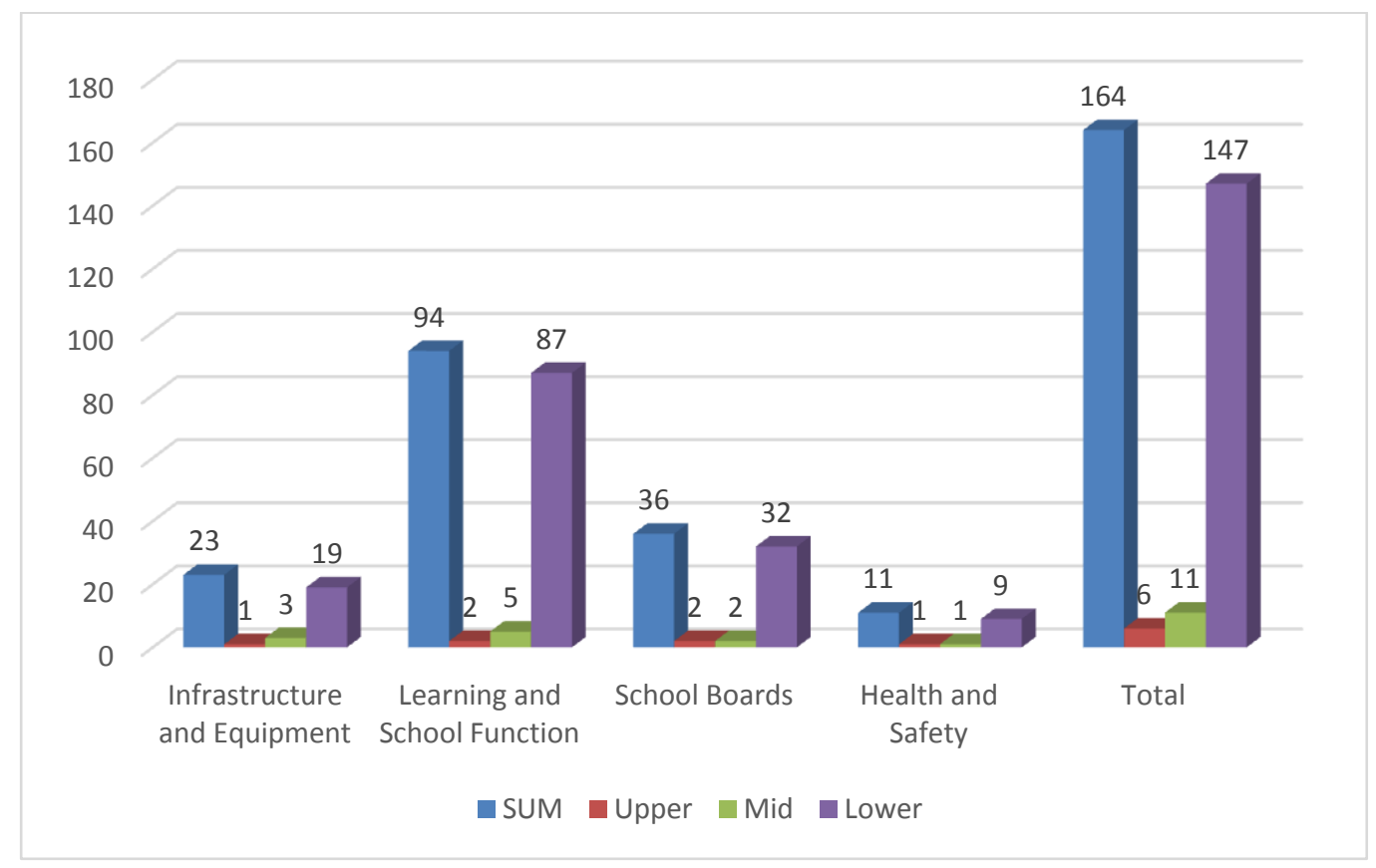

Graph 1. Legislation concerning school administration

Similar findings were seen for the second research question, which concerned legislation focusing on educators' work. This legislation, as depicted in Graph 2, focused mainly on the level of implementation, that is, the lower level of educational ontology.

With regard to the topic of teaching units, the majority of legal documents defined application issues, such as distribution of teachers' specialization, teaching sessions per week, thus forming the lower level of educational ontology. Only a small minority of relevant documents, such as curricula, which address theory, ideas and structures, can be included in the upper or mid level. With regard to professional development, most documents were found to address issues such as pensions and salary scale development. Only a few documents addressed institutions' foundation and professional development centers. It is worth indicating that all documents addressing educators' workhours and leaves were included in the lower level (Poli et al., 2010; Vas, 2007).

Legislation, therefore, defines strictly the way in which educators are required to perform their teaching work as well as the general working conditions. Educators are expected to teach in context, where many decisions such as lesson plans, teaching practices and approaches, workhours, task distributions have been legally pre-determined in a highly centralized system (Gkolia et al., 2015; OECD, 2018). This legislation, included in the lower level of ontology, significantly restricts educators' possible initiative in their role in decision 
making, forming a relevant but not so flexible school culture, similar to the dimension of school administration (Baker et al., 2009; Poli et al., 2010; Fullan, 2016).

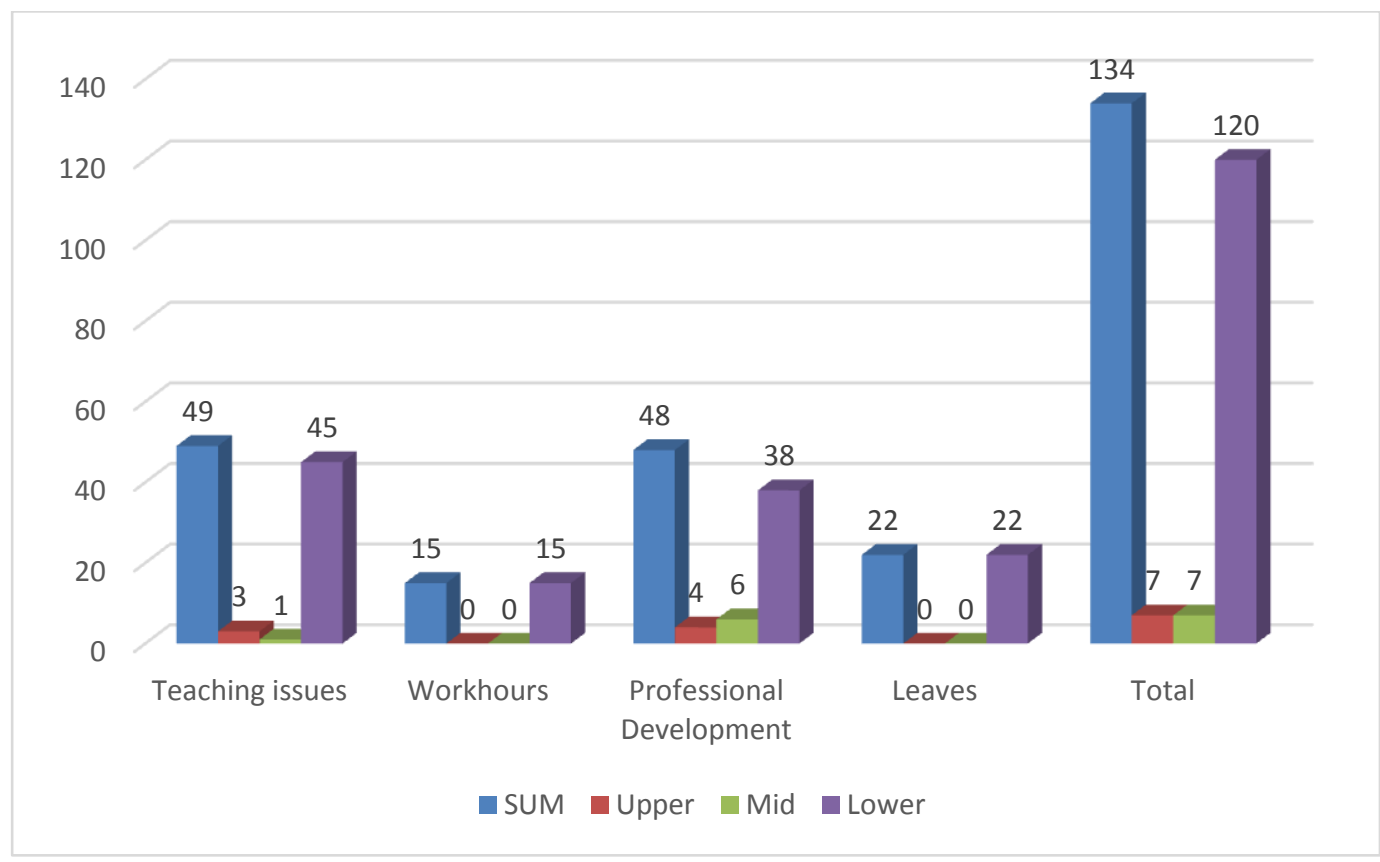

Graph 2: Legislation Concerning Educators

Finally, the findings regarding the third research question, which concerns teaching processes, were similar, as illustrated in Graph 3. As with the previous research questions, these legislations focused on the lower level of ontology, issues of application and implementation. With regard to access to higher education, certain documents can be included in the upper or mid level. These may refer to the founding of higher education institutions, routes for higher education candidates, or in general, institutions and structures concerning teaching. However, the vast majority was concerned with their implementation. As regards student evaluation and assessment, some documents referred to the establishment of assessment instruments. The majority though referred to obligations of members of the school community such as head teachers and educators toward the specific subject. Regarding teaching processes, only three documents referred to theoretical approaches or structures, such as the role of the consultant as teacher guides in this topic. Most of them referred to the way in which teaching should be conducted in practice. Finally, with regard to school visits, the majority of documents focused on how they should be planned and what they should entail. 


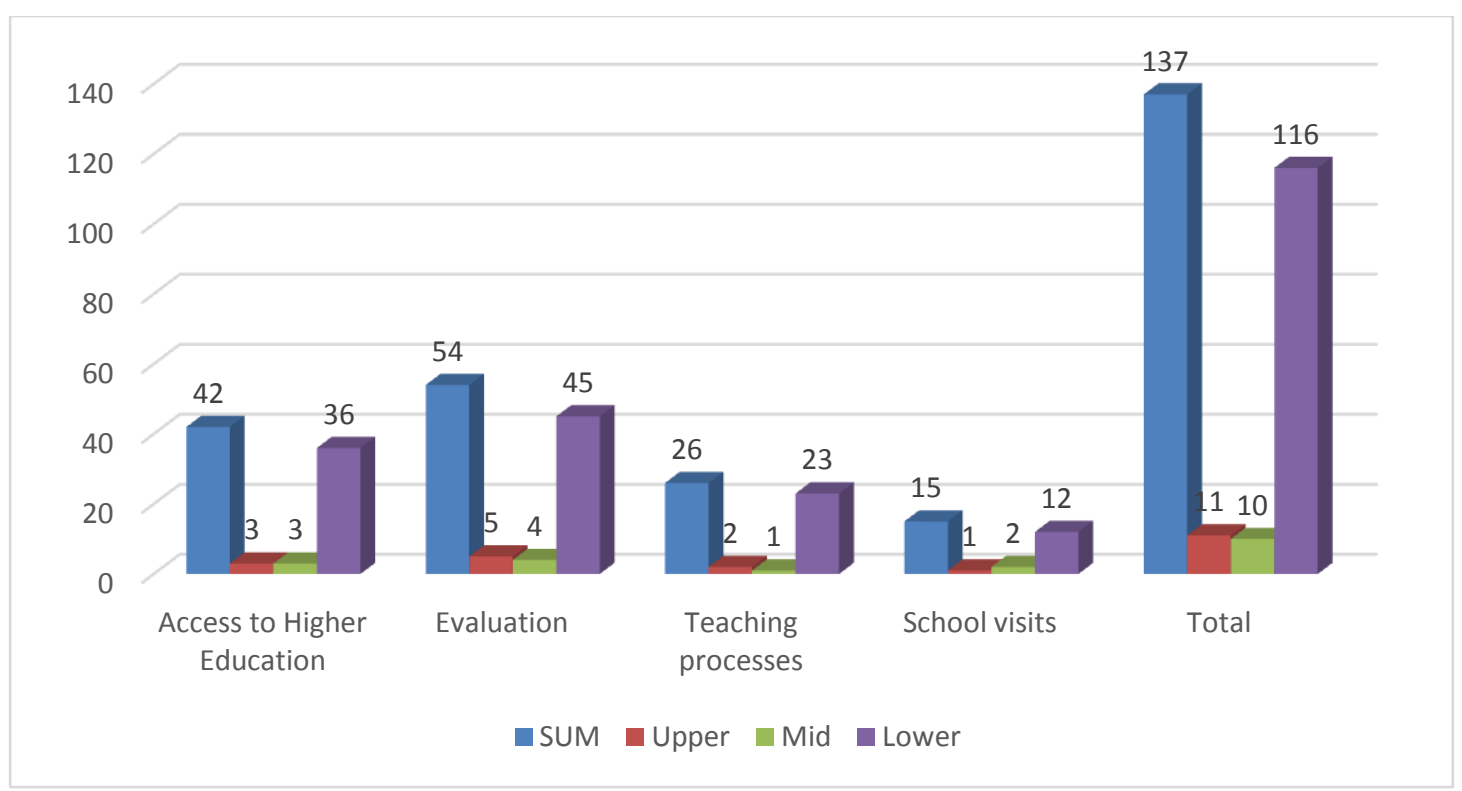

Graph 3: Legislation on learning processes.

The main conclusion drawn from the data presented above is that legislation for learning processes focused primarily on what should take place in school classrooms and how it should take place and not so much on ideas and structures defining it. This promotes a school climate and culture that has a highly controlled system for learning process (Gkolia et al., 2015; OECD, 2018). Educators and general members of the school community are not provided the concepts and theories they are expected to apply. This leads to the establishment of a culture of members who are mostly required to follow instructions for learning in a way that simply implements the detailed legislation in practice (Bass \& Riggio, 2014; Dissou et al., 2016; Fullan, 2016; Poli et al., 2010; Vas, 2007).

\section{Conclusion}

This study aimed to define the relationship between educational legislation, school culture through the prism of educational ontology. This relationship does not seem to be frequently studied in research. Ontology refers to the totality of ideas that serve as the foundations of a system such as the concept of school or the general scope of the educational structure. The basic elements of ontology can be classified as the upper level when they address the system's general theory, approach and philosophy of the system, as the mid level when they address the structures, and lastly, as the lower level when they address the application and implementation of the systems' functions (Baker et al., 2009; Poli et al., 2010; Vas, 2007). By investigating ontology through these basic elements, it was possible to perform an in-depth analysis of the system, which can contribute to any efforts for reform in the system (Fullan, 2016).

School culture reflects the general climate and conditions of the system that define the school work, educators' performance, learning process and the overall progress of education (Fullan, 2004, 2016). These aspects, though, are defined by 
educational legislation as well. Educational legislation is comprised by the legal documents that address the functions of school and educational system (Aldrich, 1992; Dissou et al., 2016; Eckstein \& Zilcha, 1994; Fang et al., 2012; Güneş, 2015; Niazov, 2018).

This study aimed to link these concepts, which are strongly affected by the context (Cohen et al., 2013; Newby, 2013; Pring, 2007). The context studied for this research was the Greek educational system, which is an example of a highly centralized educational system, where many important decisions are made by the central governing authority, the Ministry of Education (OECD, 2017, 2018).

The basic question this study aimed to answer was the level of ontology legislations in a highly centralized system focused on to create a relevant school culture. The answer was reached through a quantitative approach, involving the study of 435 legal documents concerning schools and the educational system. These documents were selected as they were available and relevant to the current state of the Greek Educational System (Gkolia et al., 2015; OECD, 2018). The primary finding was that the examined legislation focused mostly on the lower level of ontology. It is, therefore, concluded that the culture of a highly centralized educational system is formed by legislation that determines implementation and application rather than ideas, theories and structures to a great extent (Baker et al., 2009; Dissou et al., 2016; Fullan, 2016; Poli et al., 2010; Vas, 2007). This relationship was concluded through the specific study of the Greek educational system, which has been recognized as a highly centralized system (OECD, 2018).

This was achieved through an examination of formal, legal documents which should be mentioned as a limitation of this research, before any effort toward generalization of the results is made. As mentioned the reasons for that were accessibility, as well as the relevance and impact of the particular legislation in the contemporary Educational System of Greece (OECD, 2017, 2018), consequently to its' culture (Fullan, 2004, 2016). Further research involving the aspects and practices of educators and members of educational community would give more insights, around this point. This would be done on condition of time and resources, having in basis the relationship as formed in the findings (Cohen et al., 2013; Pasek, 2012; Pring, 2007).

\section{References}

Aldrich, R. (1992). Educational legislation of the 1980s in England: an historical analysis. History of education, 21(1), 57-69. https://doi.org/10.1080/0046760920210104

Alhawiti, M.M.F. \& Abdelhamid, Y. (2014). An ontology-based framework for collecting e-learning resources. International Journal of Learning, Teaching and Educational Research, 9(1), 27-40.

Baker, E., Chung, G., \& Herman, J. (2009). Ontology-based educational design: Seeing is believing. Los Angeles, CA: CRESST.

Bass, B. M., \& Riggio, R. E. (2014). Transformational leadership (2nd ed.). New York: Routledge.

Cohen, L., Manion, L., \& Morrison, K. (2013). Research methods in education (7th ed.). London, England: Routledge. https://doi.org/10.4324/9780203720967 
Dissou, Y., Didic, S. \& Yakautsava, T. (2016). Government spending on education, human capital accumulation, and growth. Economic Modelling, 58, 9-21. https://doi.org/10.1016/j.econmod.2016.04.015

Eckstein, Z., \& Zilcha, I. (1994). The effects of compulsory schooling on growth, income distribution and welfare. Journal of Public Economics, 54(3), 339-359. https://doi.org/10.1016/0047-2727(94)90040-x

Fang, H., Eggleston, K. N., Rizzo, J. A., Rozelle, S., \& Zeckhauser, R. J. (2012). The returns to education in China: Evidence from the 1986 compulsory education law (No. w18189). National Bureau of Economic Research. Retrieved from http://www.nber.org/papers/w18189 . https://doi.org/10.3386/w18189

Fullan, M. (2004). Leading in a culture of change. San Francisco, CA: Jossey-Bass

Fullan, M. (2016). The new meaning of educational change (5th ed.). London, England: Teachers College Press.

Gavrilova, T., \& Jin, H. (2008). Ontology-Based Knowledge Portal Development for University Knowledge Management. In 2008 Fourth International Conference on Networked Computing and Advanced Information Management. IEEE. https://doi.org/10.1109/ncm.2008.237

Gkolia, A., Koustelios, A., \& Belias D. (2015). Exploring the association between transformational leadership and teacher's self-efficacy in Greek education system: a multilevel SEM model. International Journal of Leadership in Education, 21(2), 176196. https:// doi.org/10.1080/13603124.2015.1094143

Gruber, R.T. (1993). A translation approach to portable ontology specifications. Knowledge Acquisition, 5(2), 199-220. https://doi.org/10.1006/knac.1993.1008

Güneş, P.M. (2015). The role of maternal education in child health: Evidence from a compulsory schooling law. Economics of Education Review, 47, 1-16. https://doi.org/10.1016/j.econedurev.2015.02.008

Hargreaves, D.H. (2001). A capital theory of school effectiveness and improvement. British Educational Research Journal, 27(4), 487-503. https://doi.org/10.1080/01411920120071489

Newby, P. (2013). Research methods for education. London, England: Routledge. https://doi.org/10.4324/9781315834627

Niazov, A. (2018). Preparing for a global society: lessons from successful education systems across the world. International Journal of Learning, Teaching and Educational Research, 17(1), 64-82. https://doi.org/10.26803/ijlter.17.1.5

OECD. (2017). Education Policy in Greece: A Preliminary Assessment. Available from http://www.oecd.org/education/Education-Policy-in-Greece-PreliminaryAssessment-2017.pdf

OECD. (2018). Education for a bright future in Greece. Reviews of national policies for education. OECD Publishing: Paris. http://dx.doi.org/10.1787/9789264298750-en

Pasek, J. (2012). Writing the empirical social science research paper: a guide for the perplexed. Psychology Teacher Network. Available from: http://www.apa.org/education/undergrad/empiricalsocial-science.pdf. https://doi.org/10.1037/e545122012-003

Poli, R., Healy, M., \& Kameas, A. (Eds.). (2010). Theory and applications of ontology: Computer applications. Netherlands: Springer. https://doi.org/10.1007/978-90$\underline{481-8847-5}$

Pring, R. (2007). Reclaiming philosophy for educational research. Educational Review, 59(3), 315-330. https:// doi.org/10.1080/00131910701427330

Schein, E.H. (2004). Organizational culture and leadership. 3rd ed. New York: Jossey Bass. 
Şenol, H. \& Lesinger, F.Y. (2018). The relationship between instructional leadership style, trust and school culture. In leadership InTech. https://doi.org/10.5772/intechopen.75950

Vas, R. (2007). Educational ontology and knowledge testing. Electronic Journal of Knowledge Management, 5(1), 123-130. Retrieved from www.ejkm.com 